\title{
Cost-effectiveness analysis of interventions to prevent cardiovascular disease in Vietnam
}

\author{
Duc Anh $\mathrm{Ha}^{1,2 *}$ and Dan Chisholm ${ }^{3}$ \\ ${ }^{1}$ Ministry of Health, 138A Giangvo, Hanoi, Vietnam, ${ }^{2}$ Boston University School of Public Health, Boston, MA, USA and ${ }^{3}$ Department of \\ Health Systems and Financing, World Health Organization, Geneva, Switzerland. E-mail: chisholmd@who.int \\ ${ }^{*}$ Corresponding author. Boston University School of Public Health, 801 Massachusetts Avenue, Boston, MA 02118, USA. \\ E-mail: ddha04@gmail.com
}

\begin{abstract}
Accepted l1 June 2010
Background Vietnam is in the process of an epidemiological transition, with cardiovascular disease (CVD) now ranked as the leading cause of death. The burden of CVD will continue to rise unless effective interventions for addressing its underlying risk factors are put in place.
\end{abstract}

Objectives To assess the costs, health effects and cost-effectiveness of a set of personal and non-personal prevention strategies to reduce CVD in Vietnam, including mass media campaigns for reducing consumption of salt and tobacco, drugs for lowering blood pressure or cholesterol, and combined pharmacotherapy for people at varying levels of absolute risk of a cardiovascular event.

Methods WHO-CHOICE methods and analytical models were employed, using local data to estimate the costs, effects and cost-effectiveness of 12 population and individual interventions implemented singly or in combination. Costs were measured in Vietnamese Dong for the year 2007 (discounted at a rate of 3\% per year), while health effects were expressed in age-weighted and discounted disability-adjusted life years (DALYs) averted.

Results A health education programme to reduce salt intake (VND 1945002 or US\$118 per DALY averted) and individual treatment of systolic blood pressure above $160 \mathrm{mmHg}$ (VND 1281596 or US\$78 per DALY averted) were found to be the most cost-effective measures for population- and individual-based approaches, respectively. Where budget is very limited, a mass media education programme on salt intake and a combination mass media programme addressing salt intake, cholesterol and tobacco should be selected first. If more resources become available, greatest population health gains can be achieved via individual treatment of systolic blood pressure and the absolute risk approach to CVD prevention.

Conclusions Contextualization of WHO-CHOICE using local data provides health decision-makers with more sound economic evidence for policy debates on prioritizing health interventions to reduce cardiovascular diseases in Vietnam. When used, cost-effectiveness analysis could increase efficiency in allocating scare resources.

Keywords Cost-effectiveness, cardiovascular disease, systolic blood pressure, cholesterol, salt intake, Vietnam 


\section{KEY MESSAGES}

- The most efficient preventive interventions to reduce risk factors for cardiovascular disease in Vietnam are highly cost-effective (each healthy year of life gained costs less than average annual income per capita).

- With no budget constraint, the single most cost-effective preventive strategy is individual treatment of systolic blood pressure over $160 \mathrm{mmHg}$, followed by combination drug therapy for individuals with an elevated risk of experiencing a CVD event over the next 10 years. If resources are highly restricted, population-based mass media strategies aimed at reducing levels of cholesterol and dietary salt intake become the most probable interventions to implement.

- Using local and context-specific information to apply generalized cost-effectiveness methods at the national level offers a promising approach to improved evidence-based health policy-making in developing countries.

\section{Introduction}

\section{Background}

Cardiovascular disease (CVD) is the leading cause of morbidity and mortality worldwide, with $80 \%$ of total deaths occurring in developing countries (WHO 2002). The most common causes of CVD morbidity and mortality are ischemic heart disease (IHD), stroke and congestive heart failure (CHF). Risk factors include, amongst other things, tobacco use, high blood pressure, high cholesterol level, high body mass index and alcohol consumption. Among these risk factors, smoking, high systolic blood pressure and cholesterol concentration account for more than $70 \%$ of the burden of CVD (Ezzati 2004).

Vietnam has been undergoing an epidemiological transition, in which the overall morbidity and mortality pattern has shifted from communicable diseases to non-communicable diseases. Increased non-communicable diseases leave the country with a double financial burden, resulting from an established high burden of infectious diseases and at the same time the escalating morbidity and mortality of non-communicable diseases such as diabetes, cancer and especially CVD. In addition, Vietnam has a very high injury burden, mainly as a result of road traffic injuries, prompting the concept of the triple burden of disease. A recent national burden of disease study conducted in 2008 ( $\mathrm{T}$ Vos, personal communication, 2009) found that cardiovascular diseases, mainly strokes and IHD, account for one-third of total deaths, and are ranked first among the top 10 leading causes of mortality. Moreover, these diseases were found to make up the largest share (approximately $20 \%$ ) of the total burden of disability-adjusted life years (DALYs) lost.

Evidence has shown that key risk factors for CVD in Vietnam are either on the rise or already at alarming levels. First, the Vietnam National Health Survey (VNHS) 2001/02 estimated that the prevalence of hypertension was $16.9 \%$ among people aged 25-65 years ( $\mathrm{MOH} 2003$ ), a 51\% increase compared with 1992. By 65 years of age around half of all men and women suffer from hypertension. Secondly, analyses using Vietnam Living Standards Survey 1992/93 and VNHS 2002/03 showed an increased trend for the prevalence of overweight and obesity (Tuan et al. 2008). In addition to this, a recently conducted study (Cuong et al. 2007) found that the prevalence of overweight and obesity in adults is $6.4 \%$ in Ho Chi Minh City, signalling an emerging public health problem in urban areas. Thirdly, cooking culture and habitual eating preferences for using salt predominantly in preserving meat and fish, and in seasoning and sauces used during cooking and at the table, make the salt intake level of the Vietnamese higher than the level recommended by the World Health Organization (WHO) of 5 grams per day (WHO 2003). Fourthly, awareness around CVD risk factors among the Vietnamese is relatively low (approximately 50\%), but considerably lower than this in rural areas (Khai et al. 2008). Finally, a smoking prevalence of $56 \%$ among Vietnamese males aged over 16 years places them among the heaviest smokers in the world (MOH 2003).

Evidently, the burden of cardiovascular diseases will continue to increase in Vietnam unless effective strategies for addressing risk factors are in place. While further increases in both internal and external financing for CVD control and prevention programmes are needed, it is extremely important for the current resources to be used efficiently. A recognized tool for guiding resource allocation is cost-effectiveness analysis. A decade ago, the WHO introduced WHO-CHOICE (CHOosing Interventions that are Cost Effective) with the intention of assisting resource allocation in the health sector, both at the global and national levels (Murray et al. 2000). Key aspects of the WHO-CHOICE approach to cost-effectiveness analysis are described in detail elsewhere (Adam et al. 2003; Edejer et al. 2003; Hutubessy et al. 2003; Lauer et al. 2003). Regional information on costs and population health effectiveness of these diseases has been made available on the WHO website (http://www.who.int/choice/en/), as are further details on the WHO-CHOICE approach and methodology.

\section{Study objective}

By applying WHO-CHOICE models and using locally available data, the overall objective of this study is to inform policy makers about the costs, effects and cost-effectiveness of preventive interventions, and how they can be combined efficiently to prevent and reduce CVD risk factors in Vietnam. Such application of WHO-CHOICE models for cost-effectiveness analysis of interventions to reduce CVD in Vietnam is promising and realistic for a couple of reasons. First, the ingredient approach developed by WHO-CHOICE allows country analysts to adapt regional-level information down to the national level. Second, several surveys such as risk factors of noncommunicable diseases and burden of disease, which have been recently carried out in Vietnam, provide valuable national demographic and epidemiological parameters for modelling population effectiveness. With respect to health policy, the contextualization of WHO-CHOICE will enable the Ministry of 


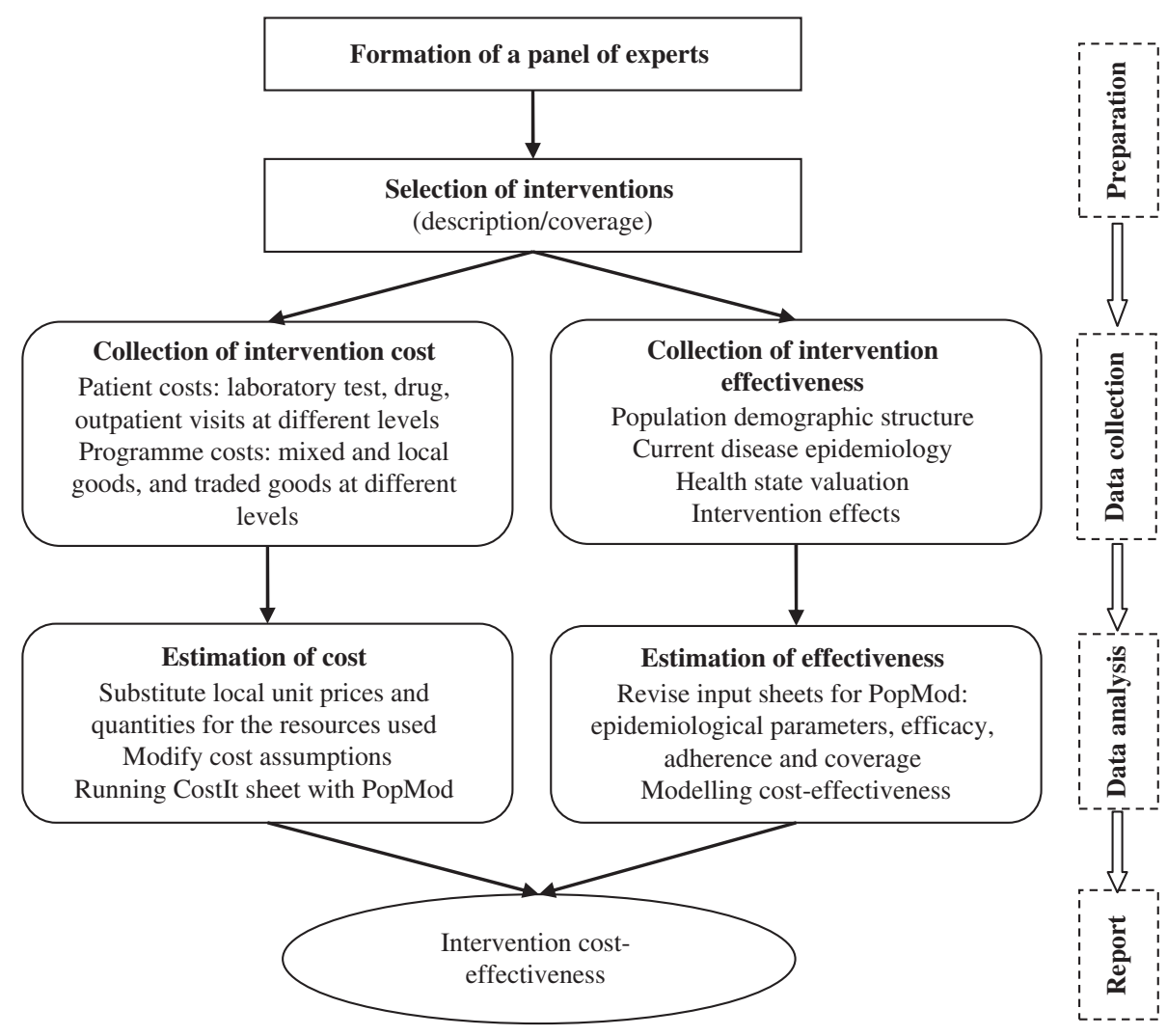

Figure 1 Methodological framework of WHO-CHOICE analysis

Health to know whether or not the resources currently devoted to cardiovascular prevention programmes achieve as much health effectiveness as they could; and how best to use additional resources if they become available.

\section{Methods and data}

\section{Overview of WHO-CHOICE contextualization process}

Figure 1 provides a methodological framework within which WHO-CHOICE estimates and models can be translated to the context of Vietnam. There are four key phases for the contextualization. In the first phase, we formed a panel of experts including Vietnamese experts in health economics, epidemiology, public health, and health communication and education. Based on their expertise and knowledge of Vietnam's health situation, the experts advised us on the selection of interventions and, more importantly, helped to re-adjust the prices and quantities provided by WHO-CHOICE, as well as the current coverage of interventions. The second and third phases involved data collection and subsequent modelling of intervention effectiveness and costs at the population level, as described in detail below. The final phase concerns the assimilation of costs and effects data into estimates of intervention cost-effectiveness, including assessment of the extent to which baseline findings are sensitive to plausible changes to key input parameters.

\section{Description of interventions and their effects}

Preventive interventions for CVD fall into two categories: population-wide and personal interventions, targeting the general population and individuals who are at high risk, respectively. The former is based on the concept that the majority of cases of CVD occur among persons with medium and low levels of risk (Rose et al. 2008). Achieving a small change in risk factors in the population at large may bring greater benefits than a large change in a sub-population of high-risk cases (Kottke et al. 1988).

Individual interventions were selected based on published studies (Murray et al. 2003; Gaziano et al. 2006), and experts' opinion (see Table 1). Population-wide interventions are comprised of three separate health education programmes aimed at reducing salt intake, cholesterol levels and tobacco consumption through mass media, together with a combined mass media strategy (for which we assumed an additive effect due to the fact that each of the individual campaigns target a specific and distinct risk factor). Health education messages are modelled to be broadcasted on television and radio channels at both central and provincial levels, as well as communicated in print via newspapers, wall posters and fliers/leaflets. In the particular case of the salt reduction strategy, we also include a voluntary agreement among manufacturers of processed foods to reduce salt content levels.

Individual interventions are divided into two sub-groups: individual treatment based on elevated levels of systolic blood pressure and cholesterol, and individual treatment based on the 


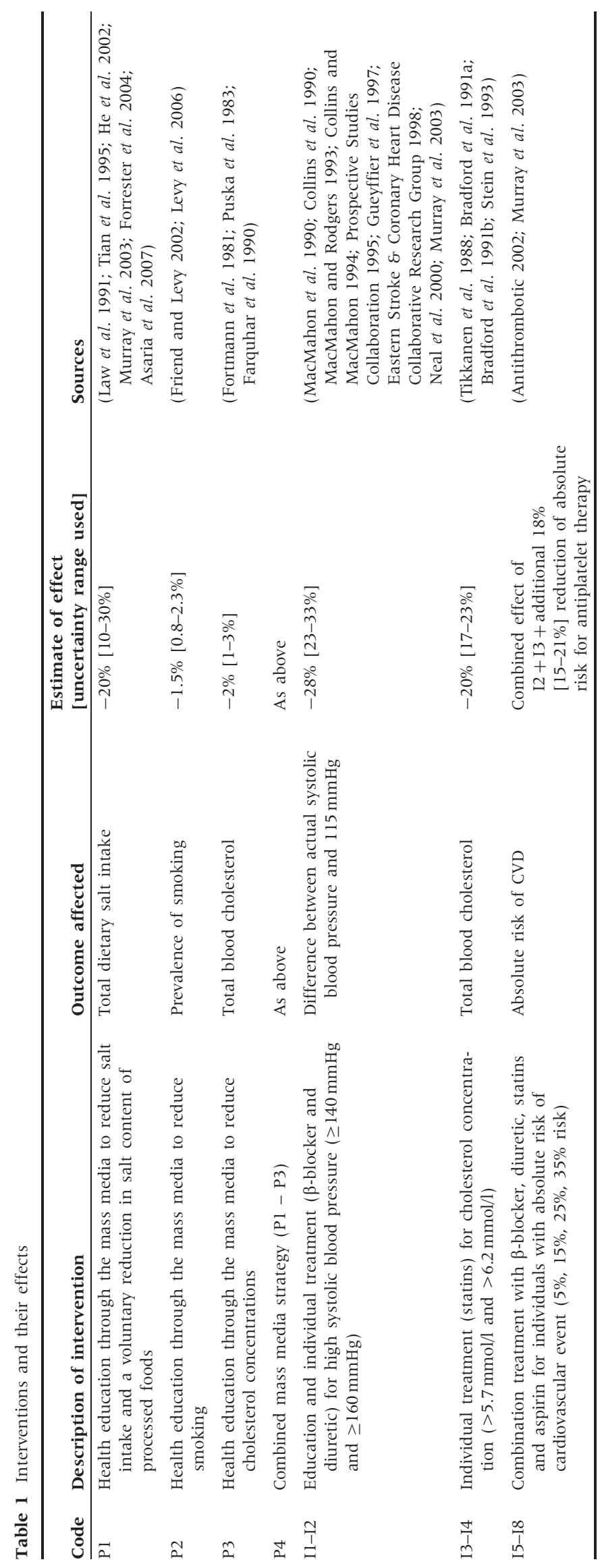

absolute risk of a cardiovascular event in the next 10 years. Individual treatment to reduce systolic blood pressure comprises a regime of $50 \mathrm{mg}$ per day atenolol and $25 \mathrm{mg}$ per day hydrochlorothiazide for those who have elevated levels of systolic blood pressure of $\geq 140 \mathrm{mmHg}$ (I1) or $>160 \mathrm{mmHg}$ (I2). Cholesterol-lowering drug treatment including $40 \mathrm{mg}$ per day simvastatin is offered for those who have elevated cholesterol for two thresholds of cholesterol concentration $>5.7$ (I3) and $\mathrm{mmol} / \mathrm{l}>6.2 \mathrm{mmol} / \mathrm{l}$ (I4). Individual treatment based on the absolute risk of a cardiovascular event over 10 years was assessed at four separate levels (5\%, 15\%, 25\% and 35\%; I5-I8), which has typically consisted of a regime of aspirin, diuretic, $\beta$-blocker and statin (Williams 2006). However, the choice of first-line drugs remains the subject of debate, especially concerning antihypertensive drugs in those without existing CVD (Antithrombotic Trialists Collaboration 2002; Dahlof et al. 2005). The regime proposed for this analysis is based on the traditionally proposed regime of $100 \mathrm{mg}$ per day aspirin, $25 \mathrm{mg}$ per day hydrochlorothiazide, $50 \mathrm{mg}$ per day atenolol and $40 \mathrm{mg}$ per day simvastatin.

Effectiveness estimates, expressed in terms of percentage improvements to the outcome of interest (such as total cholesterol level or daily salt intake), were taken from systematic reviews of randomized trials, meta-analyses and published articles on cost-effectiveness analysis (Table 1). For all individual interventions, and as advised by the panel of experts, a compliance rate of $50 \%$ was applied.

\section{Modelling the impact of CVD preventive measures on disease outcomes}

Estimation of the impact of CVD preventive strategies on final disease outcomes is quite complex, since there is a causal chain of effects that needs to be accounted for (or put another way, available evidence of intervention effect does not directly relate to a disease endpoint such as the incidence of stroke, but rather to underlying risk factors that are known to increase the probability of having a stroke). Accordingly, analysis comprised a number of steps. First, modelling was employed to estimate expected rates of disease incidence (specifically, IHD and stroke) that would occur in the population with and without the implementation of the prevention measures. This step was undertaken by means of a simulation model-based on the Asia Pacific Cohort Studies Collaboration-that applies the aforementioned effect sizes to the observed risk factor profile of different age and sex groups in the Vietnamese population (Table 2). Stata 10 (Stata Corporation, Texas, USA) was employed using a syntax specifically developed by WHOCHOICE for this process.

Second, PopMod (version 4.5), one of the WHO-CHOICE tools, was used to estimate the lifetime health gains experienced by the Vietnamese population as a result of these intervention-induced changes in disease incidence. It has been described in detail by Lauer et al. (2003). PopMod tracks what would happen to each age and sex cohort in the Vietnamese population over a lifetime period (taken to be 100 years), first without any CVD prevention measures in place and then with the various interventions in place for the initial 10 years only (after which incidence rates go back to their 'non-intervention' 
Table 2 Epidemiology of cardiovascular disease (CVD) and risk factors in Vietnam

\begin{tabular}{|c|c|c|c|c|c|c|c|c|c|c|c|c|c|}
\hline \multirow[b]{2}{*}{ Gender/age (years) } & \multicolumn{2}{|c|}{$\begin{array}{l}\text { Disease } \\
\text { incidence }\end{array}$} & \multicolumn{4}{|c|}{$\begin{array}{c}\text { Systolic blood } \\
\text { pressure (mmHg) }\end{array}$} & \multicolumn{4}{|c|}{$\begin{array}{l}\text { Total blood } \\
\text { cholesterol }(\mathrm{mmol} / \mathrm{L})\end{array}$} & \multicolumn{2}{|c|}{$\begin{array}{l}\text { Smoking } \\
\text { (prevalence) }\end{array}$} & \multirow{2}{*}{ 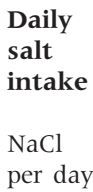 } \\
\hline & $\begin{array}{l}\text { IHD } \\
\text { (per 1000) }\end{array}$ & $\begin{array}{l}\text { Stroke } \\
(\text { per 1000) }\end{array}$ & Mean & S.D. & $\begin{array}{l}\text { Relative } \\
\text { risk for } \\
\text { IHD }\end{array}$ & $\begin{array}{l}\text { Relative } \\
\text { risk for } \\
\text { stroke }\end{array}$ & Mean & S.D. & $\begin{array}{l}\text { Relative } \\
\text { risk for } \\
\text { IHD }\end{array}$ & $\begin{array}{l}\text { Relative } \\
\text { risk for } \\
\text { stroke }\end{array}$ & Mean & $\begin{array}{l}\text { Relative } \\
\text { risk for } \\
\text { CVD }\end{array}$ & \\
\hline \multicolumn{14}{|l|}{ Male } \\
\hline $30-44$ & 0.3 & 0.1 & 117.1 & 14.9 & 1.07 & 1.09 & 4.5 & 1.1 & 3.65 & 1.48 & 0.72 & 2.43 & 11.2 \\
\hline $45-59$ & 1.0 & 0.5 & 125.9 & 20.7 & 1.05 & 1.07 & 4.6 & 1.1 & 2.08 & 1.35 & 0.68 & 2.43 & 10.8 \\
\hline $60-69$ & 2.1 & 1.9 & 133.2 & 25.5 & 1.03 & 1.05 & 4.7 & 1.2 & 1.55 & 1.25 & 0.58 & 1.84 & 10.8 \\
\hline $70-79$ & 2.3 & 2.1 & 136.1 & 27.5 & 1.02 & 1.03 & 4.8 & 1.1 & 1.42 & 1.17 & 0.47 & 1.7 & 10.8 \\
\hline $80+$ & 4.4 & 3.5 & 136.1 & 27.5 & 1.01 & 1.02 & 4.8 & 1.1 & 1.42 & 1.09 & 0.3 & 1.38 & 10.8 \\
\hline \multicolumn{14}{|l|}{ Female } \\
\hline $30-44$ & 0.5 & 0.3 & 110.6 & 14.6 & 1.07 & 1.09 & 4.3 & 1 & 3.65 & 1.48 & 0.01 & 2.43 & 10.1 \\
\hline $45-59$ & 4.5 & 3.0 & 122.4 & 20.3 & 1.05 & 1.07 & 4.8 & 1.1 & 2.08 & 1.35 & 0.03 & 2.43 & 9.7 \\
\hline $60-69$ & 20.0 & 12.3 & 132.3 & 25 & 1.03 & 1.05 & 5.1 & 1.3 & 1.55 & 1.25 & 0.05 & 1.84 & 9.7 \\
\hline $70-79$ & 40.9 & 32.6 & 136.2 & 26.9 & 1.02 & 1.03 & 5.1 & 1.2 & 1.42 & 1.17 & 0.04 & 1.7 & 9.7 \\
\hline $80+$ & 57.6 & 53.2 & 136.2 & 26.9 & 1.01 & 1.02 & 5.1 & 1.2 & 1.42 & 1.09 & 0.02 & 1.38 & 9.7 \\
\hline
\end{tabular}

Note: IHD = ischemic heart disease.

Data sources: Disease incidence: Viet Nam burden of disease study (T Vos, personal communication, 2009); Blood pressure: Viet Nam Risk Factor Surveys (Khai et al. 2008); Smoking: Vietnam National Health Survey (MOH 2003); Blood cholesterol and all relative risk estimates: The Comparative Risk Assessment Project (Ezzati 2004); Salt intake: InterSalt study (Intersalt 1998).

levels). Thus, the difference in healthy years lived (which is equivalent to the number of disability-adjusted life years or DALYs incurred) by the population with versus without intervention provides our estimate of population-level intervention effect. DALYs in the base case analysis were age-weighted and discounted at an annual rate of $3 \%$.

For the current epidemiology of IHD and stroke, including estimates of the average level of disability associated with these health conditions (on a $0-1$ scale, where 0 denotes no disability), we used data from the national burden of disease study in Vietnam ( $\mathrm{T}$ Vos, personal communication, 2009). Prevalence information of systolic blood pressure and smoking was collected from the 2001 and 2008 risk factor surveys (Khai et al. 2008) and Vietnam National Health Survey 2001/02 (MOH 2003), respectively, while the relative risks for IHD and stroke per unit increase in each risk factor were based on the estimates of WHO's Comparative Risk Assessment Project for the Western Pacific Region B (Ezzati 2004). Baseline salt intake profile was drawn from the InterSalt study (Intersalt 1988) (see Table 2). Data on demography and mortality rates by gender and age group were taken from the United Nations Population Division's Bureau for the year 2007.

\section{Intervention costs}

Costs are comprised of programme and patient-related costs. Programme costs are those incurred at the national, provincial and district administrative levels above the health facility level itself (such as training, programme administration and mass media), while patient costs are costs at the point of delivery consisting of diagnostic and laboratory tests, consultation, drugs, and hospital and health centre visits. Total costs were obtained by multiplying quantities by prices. To estimate the costs, the entire set of ingredients and their quantities developed by WHO-CHOICE for interventions to reduce CVD were re-evaluated by the local panel of experts, making them more appropriate to the context of Vietnam.

In terms of resource quantities, and in addition to the drug regimens described above, all individual preventive strategies require laboratory tests (measuring blood pressure, cholesterol concentration and blood sugar), four health care provider visits per year, and 1.5 outpatient visits per year for health education. Population-based strategies, by contrast, use up programme management staffing inputs and mass media resources (for example, six weekly TV and radio emissions at the national level and two weekly emissions in each province were modelled for the salt and tobacco campaigns).

Prices/unit costs of the ingredients were collected from a variety of sources. Concretely, prices of drugs were derived from the International Drug Price database published by Management Sciences for Health (MSH) in 2007 (Table 3) (MSH 2007). These prices were added with a mark-up of $30 \%$ for transportation and distribution, as estimated by Hutton and Baltussen (2005). Personnel payment norms were based on salary scales used by the European Union and United Nations agencies in Vietnam (UN-EU 2007) and the Government regulation (Government of Vietnam 2004). Prices of media and other IEC material were taken directly from Vietnam Television, Voice of Vietnam, local television and radio stations, and Thanh Nien publishing. Unit costs for inpatient and outpatient care were based on a Vietnamese costing study conducted at central, provincial and district levels (Flessa and Dung 2004).

A costing template (CostIt) developed by WHO-CHOICE was employed to aggregate cost components over the intervention 
Table 3 Unit costs for health intervention resource inputs

\begin{tabular}{|c|c|c|c|}
\hline Domain & Measure & Vietnamese Dong & US\$ \\
\hline \multirow[t]{2}{*}{ Secondary care } & District hospital & 11330 & 0.69 \\
\hline & Provincial hospital & 14902 & 0.91 \\
\hline \multirow[t]{2}{*}{ Primary care } & 10 minutes per visit & 19186 & 1.17 \\
\hline & 20 minutes per visit & 22880 & 1.39 \\
\hline \multicolumn{4}{|l|}{ Drugs } \\
\hline Aspirin & $100 \mathrm{mg}$ dose & 36 & 0.002 \\
\hline Atenolol & $50 \mathrm{mg}$ dose & 138 & 0.008 \\
\hline Hydrochlorothiazide & $25 \mathrm{mg}$ dose & 49 & 0.003 \\
\hline Simvastatin & $40 \mathrm{mg}$ dose & 657 & 0.04 \\
\hline \multicolumn{4}{|l|}{ Diagnostic tests } \\
\hline Renal function & & 6904 & 0.42 \\
\hline Serum lipids & & 8918 & 0.543 \\
\hline Blood glucose & & 3596 & 0.219 \\
\hline Total cholesterol & & 4890 & 0.298 \\
\hline Hepatic function & & 13233 & 0.806 \\
\hline \multicolumn{4}{|l|}{ Salaries (gross per year) } \\
\hline Nurses & & 39503128 & 2406 \\
\hline Health worker & & 22981595 & 1400 \\
\hline Medical specialist & & 91895543 & 5596 \\
\hline Medical officer & & 63744761 & 3882 \\
\hline Programme director & & 91895543 & 5596 \\
\hline Programme manager & & 63744761 & 3882 \\
\hline Administration officer & & 39503128 & 2406 \\
\hline Secretary/receptionist & & 22981595 & 1400 \\
\hline \multicolumn{4}{|l|}{ Media (national level) } \\
\hline Television time & 1 minute & 21067271 & 1282.95 \\
\hline Radio time & l minute & 2532665 & 154.23 \\
\hline Newspapers & l/4 page advertisement & 17585554 & 1070.92 \\
\hline Wall posters & l square metre & 6589 & 0.40 \\
\hline Flyers/leaflets & A4 size & 1387 & 0.08 \\
\hline \multicolumn{4}{|l|}{ Media (provincial level) } \\
\hline Television time & 1 minute & 3805795 & 231.77 \\
\hline Radio time & 1 minute & 457525 & 27.86 \\
\hline Newspapers & l/4 page advertisement & 3176824 & 193.47 \\
\hline Wall posters & l square metre & 6589 & 0.40 \\
\hline Flyers/leaflets & A4 size & 1387 & 0.08 \\
\hline Per diems (national level) & & 395042 & 24 \\
\hline
\end{tabular}

Sources: Drug prices: MSH (2007); inpatient and outpatient care: Flessa and Dung (2004); salaries: UN-EU (2007) and Government of Vietnam (2004); media and other IEC material prices: from Vietnam Television, Voice of Vietnam, local television and radio stations, and Thanh Nien publishing.

implementation horizon (10 years). All costs beyond the base year were discounted at a rate of $3 \%$ per year, consistent with other guidelines (Gold et al. 1996; Drummond 2005). Capital and start-up costs were likewise annualized over the assumed life-time of the intervention. Moreover, to adjust for capacity utilization, we assumed a norm of $80 \%$ for capacity utilization as recommended by WHO-CHOICE. Throughout this paper, all costs were estimated using societal perspective and Vietnamese Dong (VND) with an exchange rate of US\$1 = VND 16421 for the base year 2007.

\section{Calculating cost-effectiveness}

When calculating cost-effectiveness ratios, we considered what would happen from today if all resources could be re-allocated. Put another way, the cost-effectiveness of each interventions was assessed in relation to the null or counterfactual scenario, in which none of the proposed interventions was implemented; this is the average costeffectiveness ratio. In addition, we calculated incremental cost-effectiveness ratios for (non-dominated) interventions that fall on the efficiency frontier or cost-effectiveness 
expansion path (see Figure 2 for a graphical demonstration of this concept).

Classification of cost-effective interventions was based on the suggestions from the Commission on Macroeconomics and Health (CMH) (WHO 2001), in which to be considered cost-effective, an intervention has to have a cost-effectiveness ratio of less than three times gross domestic product (GDP) per capita. Below that threshold, WHO-CHOICE considers an intervention to be very cost-effective if each DALY can be averted at a cost of less than GDP per capita (which in the Vietnamese context was VND 13456000 or US\$820 in 2007). Since this is a country-specific economic analysis, we report results using local currency units, but make regular conversions to US dollars to help those unfamiliar with Vietnamese Dong.

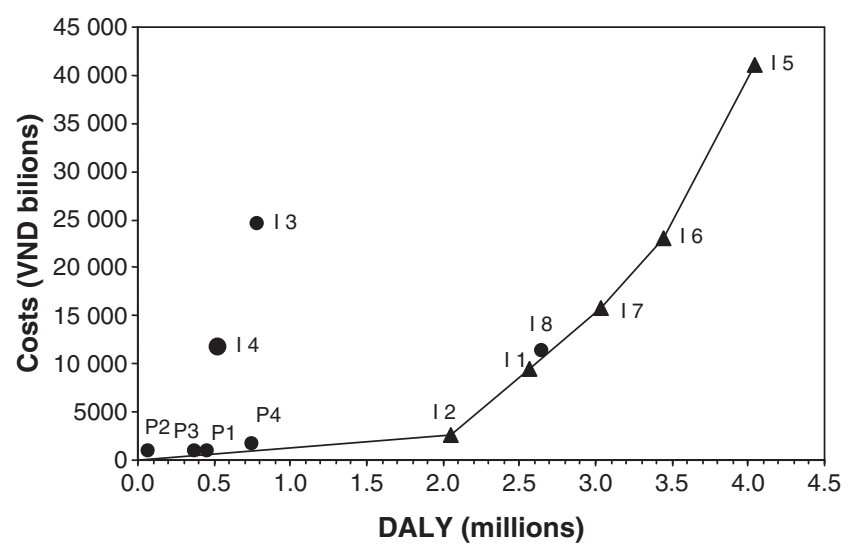

Figure 2 Expansion path for cardiovascular disease interventions. Note: DALY $=$ disability-adjusted life year.

\section{Uncertainty analysis}

We assessed sensitivity analyses on the health effects of various interventions using the lower and upper limits (Table 1) and also the effect of changes in prices (from a half to double the base estimates). We also recalculated the cost-effectiveness ratios without age weight and discounting. Best-case and worst-case scenario analyses were undertaken using lower health effect limits and highest drug prices (worst-case), and upper health effect limits and lowest drug prices (best-case). Finally, we did a probabilistic, multivariate sensitivity analysis using Monte Carlo League (MCLeague) software (another of the WHO-CHOICE tools), assuming a coefficient of variation of $15 \%$ on the cost side and $25 \%$ on the effectiveness side with 1000 randomly selected sets of variables.

\section{Results}

Table 4 represents total annual costs and health effectiveness in terms of age-weighted and discounted DALYs averted, the average cost-effectiveness ratio, incremental cost-effectiveness ratio, and the cost-effectiveness category for all 23 interventions. The least costly interventions are health education programmes through mass media, with a total cost per year of VND 89 billion (US\$0.06 per capita). By contrast, combination drug treatment for individuals with a $5 \%$ absolute risk of a cardiovascular event is the most costly intervention (VND 4121 billion/year, equivalent to US $\$ 2.9$ per capita). In terms of effectiveness, individual interventions save more DALYs than population-wide interventions, but are more costly. Specifically, population interventions can avert 7000-75000 DALYs per year when implemented singly or in combination, while individual interventions can save 50000-400 000 DALYs annually.

According to the Commission on Macroeconomics and Health's classification, all interventions are cost-effective, i.e. below the threshold of three times GDP per capita.

Table 4 Annual cost, effects and cost-effectiveness of interventions

\begin{tabular}{|c|c|c|c|c|c|}
\hline Intervention & $\begin{array}{l}\text { Costs per year } \\
\text { (VND, billions) }\end{array}$ & $\begin{array}{l}\text { DALYs averted } \\
\text { per year }\end{array}$ & $\begin{array}{l}\text { ACER } \\
\text { (VND per DALY saved) }\end{array}$ & $\begin{array}{l}\text { ICER } \\
\text { (VND per DALY saved) }\end{array}$ & $\begin{array}{l}\text { CMH } \\
\text { category* }\end{array}$ \\
\hline Media salt campaign & 89 & 45939 & 1945002 & Dominated & $\overline{\text { Very cost-effective }}$ \\
\hline Media smoking campaign & 89 & 7250 & 12324059 & Dominated & Very cost-effective \\
\hline Media cholesterol campaign & 89 & 36982 & 2416075 & Dominated & Very cost-effective \\
\hline Mass media combination & 167 & 75379 & 2211140 & Dominated & Very cost-effective \\
\hline Treatment of SBP $>140 \mathrm{mmHg}$ & 941 & 256559 & 3660315 & 13194115 & Very cost-effective \\
\hline Treatment of SBP $>160 \mathrm{mmHg}$ & 264 & 205329 & 1281596 & 1281596 & Very cost-effective \\
\hline Treatment of cholesterol $>5.7 \mathrm{mmol} / \mathrm{l}$ & 2460 & 78179 & 31469764 & Dominated & Cost-effective \\
\hline Treatment of cholesterol $>6.2 \mathrm{mmol} / \mathrm{l}$ & 1174 & 52392 & 22404550 & Dominated & Cost-effective \\
\hline Combination treatment ( $>5 \%$ risk) & 4121 & 404684 & 10157911 & 30240689 & Very cost-effective \\
\hline Combination treatment ( $>15 \%$ risk) & 2308 & 344868 & 6674633 & 17547288 & Very cost-effective \\
\hline Combination treatment ( $>25 \%$ risk) & 1584 & 303714 & 5201348 & 13585810 & Very cost-effective \\
\hline Combination treatment ( $>35 \%$ risk) & 1129 & 264716 & 4251785 & Dominated & Very cost-effective \\
\hline
\end{tabular}

Notes: ACER = average cost-effectiveness ratio; ICER $=$ incremental cost-effectiveness ratio; DALY= disability-adjusted life year; $\mathrm{CMH}=\mathrm{Commission}$ on Macroeconomics \& Health; SBP = systolic blood pressure.

*Very cost-effective: <GDP per capita; Cost-effective: <3 times GDP per capita; Not cost-effective: >3 times GDP per capita.

GDP per capita in Vietnam for the year 2007 was VND 13465000 (US\$820). 


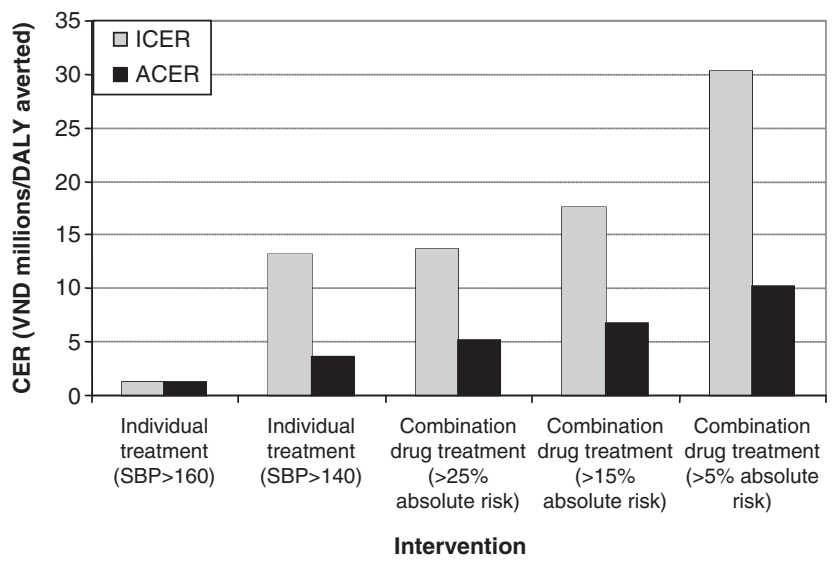

Figure 3 Incremental and average cost-effectiveness ratios for the most cost-effective interventions. Notes: CER $=$ cost-effectiveness ratio; ICER $=$ incremental cost-effectiveness ratio; ACER $=$ average cost-effectiveness ratio; DALY = disability-adjusted life year; $\mathrm{SBP}=$ systolic blood pressure.

Furthermore, all population interventions implemented either in isolation or in combination are very cost-effective (below the threshold of GDP per capita). Among the population interventions, the health education programme to reduce salt intake is the most cost-effective (VND 1945002 or US\$118 per DALY averted), followed by the mass media combination programme (VND 2211140 or US\$135 per DALY averted). For individual interventions, results show that both treatment interventions based on elevated levels that aim to reduce cholesterol are less cost-effective when compared with all other measures. Individual treatment for cholesterol $>5.7 \mathrm{mmol}$ is least cost-effective (VND 31469764 or US\$1916 per DALY averted). Conversely, treatment of systolic blood pressure $>160 \mathrm{mmHg}$ is the most cost-effective measure (VND 1281596 or US\$78 per DALY averted). With regard to the absolute risk approach, both cost and cost-effectiveness ratios are disproportional to the increase of the risk thresholds.

Figure 2 plots the total costs and effects of all single or combined interventions based on point estimates. The solid line, the expansion path, connects the most cost-effective interventions which would be selected in order to achieve greatest health gain given increasing levels of available resources. The movement would start with individual treatment of systolic blood pressure $>160 \mathrm{mmHg}$ (I2) at the budget level of VND 264 billion per year (US\$16.1 million) and then move to individual treatment of systolic blood pressure $>140 \mathrm{mmHg}$ (I1). If additional resources became available, combined treatment for those who have an absolute risk of a CVD event in the next 10 years of $25 \%$ (I7), $15 \%$ (I6) and 5\% (I5) should be purchased, respectively. Incremental and average costeffectiveness ratios for the best individual interventions are shown in Figure 3.

Results of one-way sensitivity analysis and worst/best-case scenario analysis are represented in Table 5. Without age weights and discounting, average cost-effectiveness ratios reduced more than a half, moving almost all interventions to the very-cost effective category, except for individual treatment of cholesterol $>5.7 \mathrm{mmol}$. With lower estimates of effect sizes, significant increases in average cost-effectiveness ratios of both population and individual interventions to reduce cholesterol were recorded. Notably, health education programme to reduce smoking was very sensitive, moving from very cost-effective to the cost-effective category (VND 12324059 per DALY versus VND 29574642 per DALY averted). Higher effect sizes did not have much effect on overall average cost-effectiveness ratios, in the sense that they did not move interventions to reduce cholesterol to the very cost-effective category. While no significant changes were recorded when halving the base drug prices, we found that when drug prices were doubled, individual treatment to reduce cholesterol $>5.7$ is no longer cost-effective, and combination drug treatment for absolute risk of CVD over $5 \%$ moves from very cost-effective to the cost-effective category.

Overall, the combination of lower health effects and double drug prices (worst-case) made all interventions least costeffective. In the worst-case scenario, both individual treatments of cholesterol above 5.7 and $6.2 \mathrm{mmol}$ were not cost-effective (VND 61554243 per DALY and VND 43643450 per DALY averted, respectively), and media smoking campaign and combination treatment for above 5\% absolute risk moved from very cost-effective to cost-effective. On the contrary, in the best-case scenario, all interventions were very cost-effective, except individual treatment of cholesterol $>5.7$ which still remained in the cost-effective category. Results of sensitivity analyses showed that individual treatment of systolic blood pressure $>160 \mathrm{mmHg}$ is always the first choice based on point estimates, and the most commonly chosen expansion path $(60 \%)$ is the combination of individual treatment of systolic blood pressure $>160 \mathrm{mmHg}$ and combination treatment of absolute risks of $25 \%, 15 \%$ and $5 \%$, respectively.

Probabilistic, multivariate sensitivity analysis showed the range of possible point estimates for the expansion path is very wide and there are overlaps between uncertainty intervals (Figure 4). As a result, there is much uncertainty about the choice of interventions. An alternative solution is to use a stochastic league table produced by MCLeague. Figure 5 summarizes the likelihood that a single or combined intervention is selected to maximize health gain at a given available level of budget, creating a stochastic budget expansion path. At the budget level of less than VND 170 billion per year (US\$10.4 million), a health programme to reduce salt intake is chosen in a range of $40-70 \%$ probability of being cost-effective. As resources available increase up to VND 250 billion per year (US\$15.2 million), the mass media combination programme is added with a probability ranging from $50-80 \%$. The coverage expands to individual treatment of systolic blood pressure $>160 \mathrm{mmHg}$ as the budget increases over VND 270 billion per year.

\section{Discussion}

Results of this analysis demonstrate that all population-wide interventions and the majority of individual measures focusing on reducing risk factors of CVD are very cost-effective. Where resources are scare (less than VND 250 billion per year), a health education programme to reduce salt intake and a combined mass media programme (on salt, tobacco and cholesterol) are the most cost-effective measures and should be purchased first. As more resources are made available, 


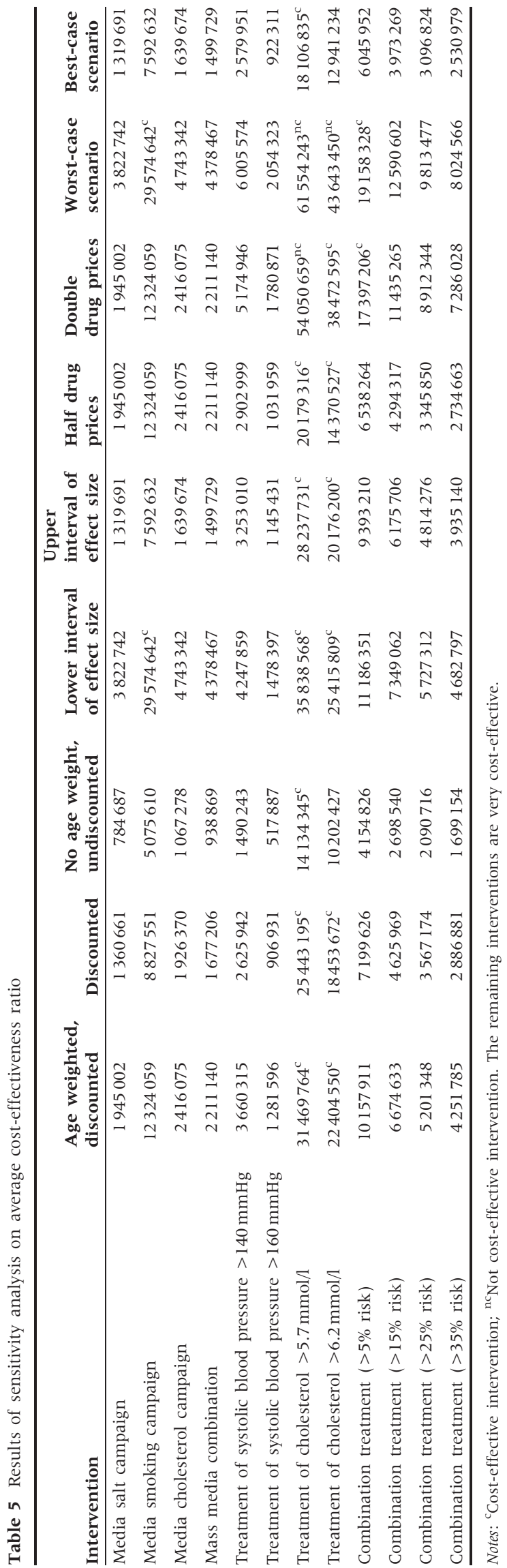

individual treatment of systolic blood pressure $>160 \mathrm{mmHg}$ and combination treatment based on absolute risks of a cardiovascular event of $25 \%, 15 \%$ and $5 \%$ in the next 10 years could then be potentially implemented in Vietnam.

Our findings shared many, but not all, similarities with recent cost-effectiveness analyses of interventions to reduce cardiovascular diseases. They are consistent with what were estimated by Murray et al. (2003) for the Western Pacific Region B, to which Vietnam belongs, except for interventions to reduce cholesterol (I3-I4). While Murray et al. found cholesterol-lowering drug interventions are very cost-effective, we found them merely cost-effective, even not cost-effective when drug prices were doubled. Moreover, our average cost-effectiveness estimates are significantly higher than the regional estimates, due to higher costs and lower health effectiveness. These divergences emphasize the importance of using local and context-specific information to support national priority-setting efforts. Finally, our interventions based on the absolute risk approach using a multi-drug regimen had similar cost-effective results to recent analyses conducted for and in developing countries (Gaziano et al. 2006; Rubinstein et al. 2009).

Our application of WHO-CHOICE to Vietnam has several caveats. First, although we made use of much local data on costs and epidemiology, no national data on the epidemiology of sodium consumption was available. In the absence of this information, we therefore derived epidemiology and effect estimates from other international studies and then worked with the panel of experts to determine conservative estimates in order to adjust to the context of Vietnam. Secondly, we did not incorporate in the models other benefits, i.e. decrease in the risk of gastric cancer due to reduced salt intake (Tsugane et al. 2004; Tsugane 2005), or resistance which may be caused by platelet-active drugs (Patrono et al. 2004).

Importantly, this paper has several implications for the policy debate on prevention and control of CVD in Vietnam. First, like other developing countries, Vietnam faces serious financial constraints. A recent report has revealed that, amongst other things, the national budget for health care is unable to meet the people's health care needs, the effectiveness of utilization of the state budget is still limited, and more importantly, resources spent on preventive medicine are far from adequate $(\mathrm{MOH}$ 2008). As a result, spending the health budget wisely and efficiently has become increasingly important. Our results provide health policy-makers with more information on what prevention strategies to reduce CVD are cost-effective and how they should be purchased if additional resources are available, thereby increasing efficiency in resource allocation. Specifically, according to the request of the $\mathrm{MOH}(\mathrm{MOH} 2007)$, the budget allocated for CVD prevention and control was about VND 80 billion in 2008 (US\$4.7 million). At this budget level, the mass media campaign to increase population awareness of the risk factors of CVD, such as salt intake and high cholesterol concentration, should be the first choice. In the long run, ideally cardiovascular health promotion should be a part of the national media strategy. This suggestion was also recommended for the South Asia countries, which, along with Vietnam, are in the second stage of the epidemiologic transition (Nishtar 2002). 


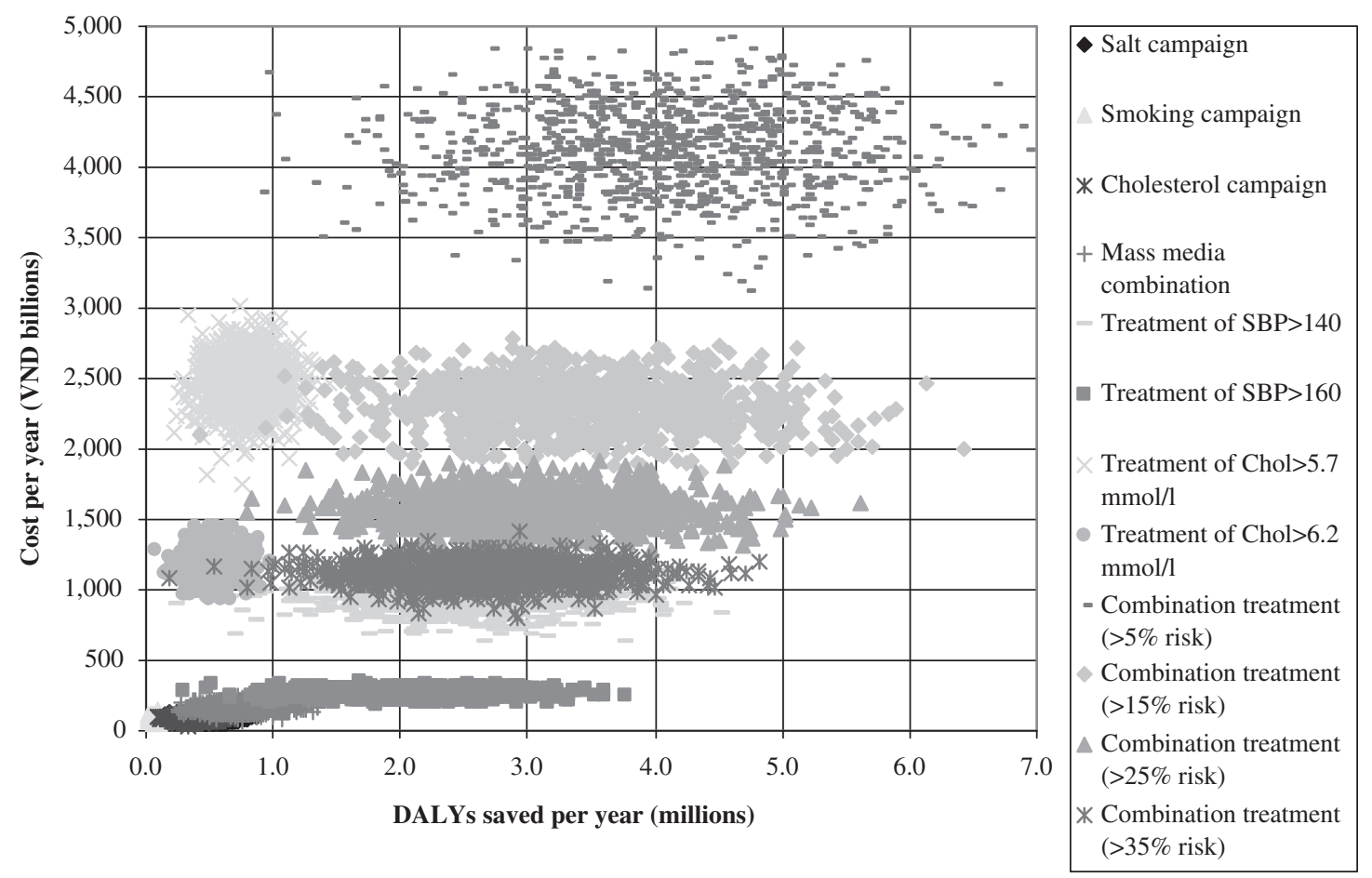

Figure 4 Uncertainty around incremental cost-effective ratios. Notes: DALYs=disability-adjusted life years; SBP=systolic blood pressure; Chol $=$ cholesterol.

Secondly, as the budget allocated for the control and prevention of CVD is projected to increase in the coming years, it is recommended that health policy-makers expand the individual prevention treatment of systolic blood pressure, especially for those who have elevated levels over $160 \mathrm{mmHg}$ (which is the most cost-effectiveness intervention). While the extensive development of pharmacies throughout the country would make the scale-up of pharmaceutical interventions more feasible and less costly, and the recent achievement in the expansion of health insurance coverage through several special programmes targeting poor and less affluent people was found to increase access to health care (Ekman et al. 2008), there remains some debate around screening for risk factors and adherence to treatment. For example, for those who have high systolic blood pressure, adherence to the life-long treatment regime with two or more antihypertensive agents could be affected by cultural preferences and beliefs (Betancourt et al. 1999), clinical inertia (O'Connor 2003), clinician-patient partnership (Barrier et al. 2003), and economic barriers (Bovet et al. 2002). Therefore, when implemented, these issues should not be neglected. These same issues also apply to the administration of combination pharmacotherapy to those at an absolute risk of experiencing a CVD event in the next 10 years, particularly the latter economic constraint given the higher per capita cost of implementation (e.g. US\$1.13 per capita population for the $25 \%$ risk level). This estimate is nearly double that made in a recent modelling study of the financial costs (and health effects) of scaling-up a multi-drug regimen in developing countries, including Viet Nam (US\$0.66 per capita at 2005 price levels; Lim et al. 2007).
Thirdly, not only are the suggested prevention measures very cost-effective, but they seem highly feasible in other aspects, particularly from a financial perspective since estimated implementation costs are very low (less than a dollar per capita per year for the most cost-effective strategies). Part of the reason for this financial viability is that all drugs used for treating hypertension and hyperlipidemia are now off-patent, available widely across the country and can therefore be easily scaled up through primary health care or outpatient clinics. Finally, an education programme through mass media to reduce sodium intake is highly recommended by WHO in the recent Forum and Technical Meeting (WHO 2007). In Vietnam, such a measure may prove to be even more effective because the overall knowledge of risk factors for CVD among the Vietnamese people remains relatively low.

Applying WHO-CHOICE using local and context-specific information is a promising approach to improved evidencebased health policy-making in developing countries where data are limited and technical skills are scarce. The following are some lessons learned from our application which other analysts might find useful:

- first, a good panel of local experts representing multiple disciplines plays an important role in guiding interventions and providing insight into how to adjust WHO-CHOICE information for the specific national context;

- second, it is important to fully understand how an intervention pathway reflects the underlying biological process of the disease question and the impact of the intervention (i.e. from the developed intervention pathways, ingredients used in the pathway are documented and then 


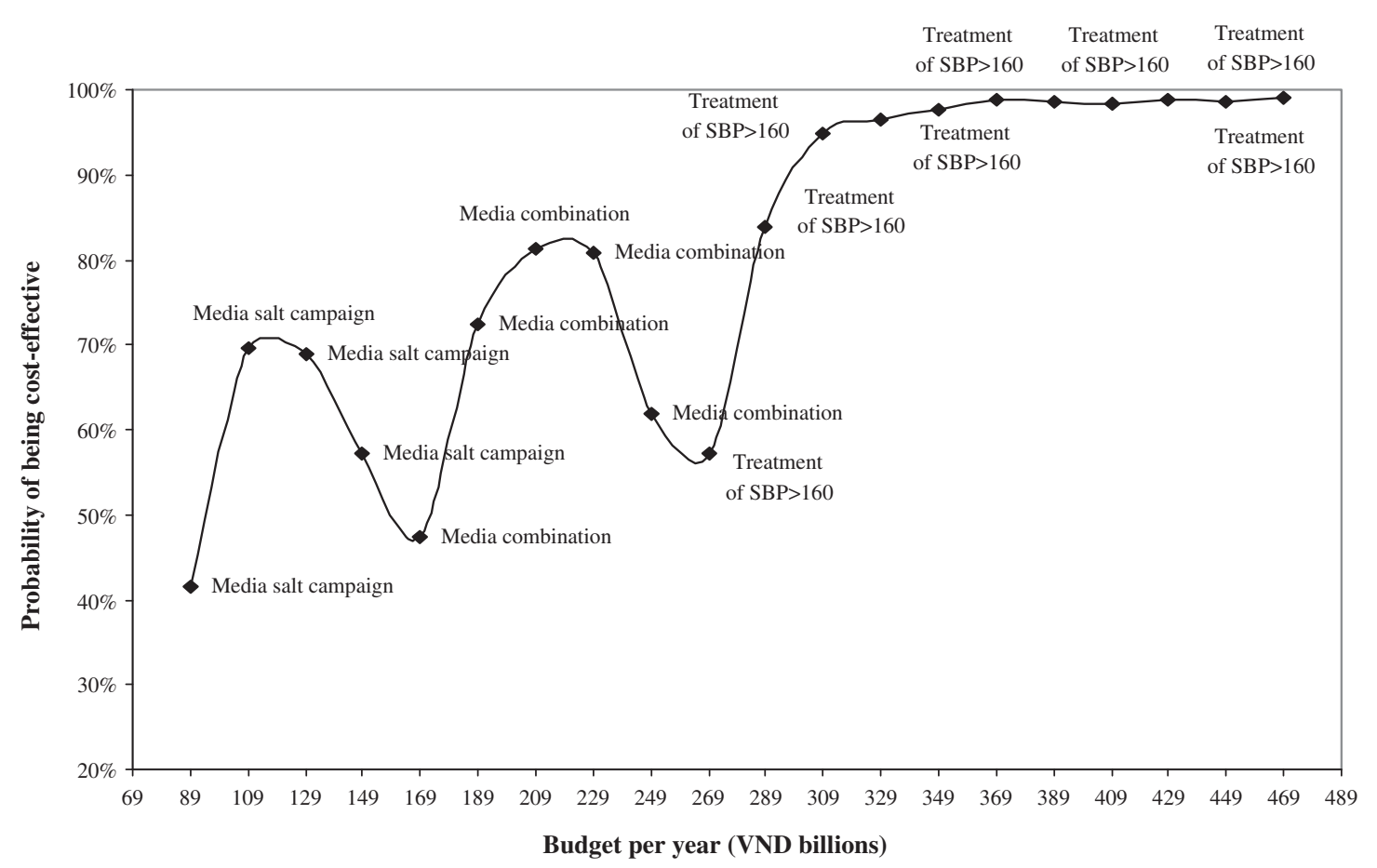

Figure 5 Stochastic budget expansion path Note: SBP = systolic blood pressure.

the amount of resources used in the intervention is estimated);

- finally, conducting an economic evaluation using modelling requires that appropriate evidence be elicited from multiple and disparate sources (as opposed to cost-effectiveness analysis undertaken alongside clinical trials). As a rule of thumb, the evidence should not be identified selectively, but derived from the best designed and least biased sources.

\section{Conclusion}

As cardiovascular diseases are escalating in Vietnam where resources are very limited, there exists a constant tension over how available resources can be used to best effect. Our analysis brings fresh and practical evidence to policy debates on prevention and control of cardiovascular diseases. Although final decisions may be based on other grounds such as social and geographical equity, cost-effectiveness is among the key inputs and plays a unique role in how to allocate scare resources. Using the results of this analysis would lead to policy making in Vietnam being driven more by evidence, thereby making decisions more explicit and systematic.

\section{Acknowledgements}

We would like to thank Vietnam Health Strategy and Policy Institute, The School of Population Health at the University of Queensland, Non-Communicable Disease Program, National Heart Institute, Department of Health System and Financing,
WHO-Geneva, and WHO office in Hanoi for their support and for sharing data.

This work was funded in part by a grant from the Vietnam Education Foundation (VEF), Jiaikai Foundation, and the Developing Evidence Base for Health Policy in Vietnam (VINE) project funded by Atlantic Philanthropies.

\section{Disclaimer}

The views expressed in this paper are solely the responsibility of the named authors and do not necessarily reflect the decisions or stated policy of the organizations they work for.

\section{References}

Adam T, Evans DB, Murray CJ. 2003. Econometric estimation of country-specific hospital costs. Cost Effectiveness and Resource Allocation 1: 3 .

Antithrombotic Trialists Collaboration. 2002. Collaborative meta-analysis of randomised trials of antiplatelet therapy for prevention of death, myocardial infarction, and stroke in high risk patients. British Medical Journal 324: 71-86.

Asaria P, Chisholm D, Mathers C et al. 2007. Chronic disease prevention: health effects and financial costs of strategies to reduce salt intake and control tobacco use. The Lancet 370: 2044-53.

Barrier PA, Li JTC, Jensen NM. 2003. Two words to improve physician-patient communication: what else? Mayo Clinic Proceedings 78: 211-6.

Betancourt JR, Carrillo JE, Green AR. 1999. Hypertension in multicultural and minority populations: linking communication to compliance. Current Hypertension Reports 1: 482-8. 
Bovet P, Burnier M, Madeleine G et al. 2002. Monitoring one-year compliance to antihypertension medication in the Seychelles. Bulletin of the World Health Organization 80: 33-9.

Bradford RH, Shear CL, Chremos AN et al. 1991a. Expanded Clinical Evaluation of Lovastatin (EXCEL) study results: I. Efficacy in modifying plasma lipoproteins and adverse event profile in 8245 patients with moderate hypercholesterolemia. Archives of Internal Medicine 151: 43-9.

Bradford RH, Shear CL, Chremos AN et al. 1991b. Expanded Clinical Evaluation of Lovastatin (EXCEL) study results: III. Efficacy in modifying lipoproteins and implications for managing patients with moderate hypercholesterolemia. American Journal of Medicine 91: $18 \mathrm{~S}-24 \mathrm{~S}$

Collins R, MacMahon S. 1994. Blood pressure, antihypertensive drug treatment and the risks of stroke and of coronary heart disease. British Medical Bulletin 50: 272-98.

Collins R, Peto R, MacMahon S et al. 1990. Blood pressure, stroke and coronary heart disease. Part 2: Short-term reductions in blood pressure: overview of randomised drug trials in their epidemiological context. The Lancet 335: 827-38.

Cuong TQ, Dibley MJ, Bowe S et al. 2007. Obesity in adults: an emerging problem in urban areas of Ho Chi Minh City, Vietnam. European Journal of Clinical Nutrition 61: 673-81.

Dahlof B, Sever PS, Poulter NR et al. 2005. Prevention of cardiovascular events with an antihypertensive regimen of amlodipine adding perindopril as required versus atenolol adding bendroflumethiazide as required, in the Anglo-Scandinavian Cardiac Outcomes Trial-Blood Pressure Lowering Arm (ASCOT-BPLA): a multicentre randomised controlled trial. The Lancet 366: 895-906.

Drummond MF. 2005. Methods for the Economic Evaluation of Health Care Programmes. Oxford: Oxford University Press.

Eastern Stroke and Coronary Heart Disease Collaborative Research Group. 1998. Blood pressure, cholesterol, and stroke in eastern Asia. The Lancet 352: 1801-7.

Edejer TTT, Baltussen R, Adam T et al. 2003. WHO Guide to Cost-Effectiveness Analysis. Geneva: World Health Organization.

Ekman B, Liem NT, Duc HA et al. 2008. Health insurance reform in Vietnam: a review of recent developments and future challenges. Health Policy and Planning 23: 252-63.

Ezzati M. 2004. Comparative Quantification of Health Risks: Global and Regional Burden of Disease Attributable to Selected Major Risk Factors. Geneva: World Health Organization.

Farquhar JW, Fortmann SP, Flora JA et al. 1990. Effects of communitywide education on cardiovascular disease risk factors. The Stanford Five-City Project. The Journal of the American Medical Association 264: 359-65.

Flessa S, Dung NT. 2004. Costing of services of Vietnamese hospitals: identifying costs in one central, two provincial and two district hospitals using a standard methodology. International Journal of Health Planning and Management 19: 63-77.

Forrester T, Adeyemo A, Soarres-Wynter S et al. 2004. A randomized trial on sodium reduction in two developing countries. Journal of Human Hypertension 19: 55-60.

Fortmann SP, Williams PT, Hulley SB et al. 1981. Effect of health education on dietary behavior: the Stanford Three Community Study. American Journal of Clinical Nutrition 34: 2030-8.

Friend K, Levy DT. 2002. Reductions in smoking prevalence and cigarette consumption associated with mass-media campaigns. Health Education Research 17: 85-98.

Gaziano TA, Opie LH, Weinstein MC. 2006. Cardiovascular disease prevention with a multidrug regimen in the developing world: a cost-effectiveness analysis. The Lancet 368: 679-86.
Gold MR, Siegel JE, Russell LB et al. 1996. Cost-Effectiveness in Health and Medicine. New York: Oxford University Press.

Government of Vietnam. 2004. Resolution of the Government No. 204/ 2004/NĐ-CP dated December 14, 2004 on salary scale of civil servant. Hanoi: Government of Vietnam.

Gueyffier F, Boutitie F, Boissel JP et al. 1997. Effect of antihypertensive drug treatment on cardiovascular outcomes in women and men: a meta-analysis of individual patient data from randomized, controlled trials. Annals of Internal Medicine 126: 761-7.

He FJ, MacGregor GA. 2002. Effect of modest salt reduction on blood pressure: a meta-analysis of randomized trials. Implications for public health. Journal of Human Hypertension 16: 761-70.

Hutton G, Baltussen R. 2005. Cost valuation in resource-poor settings. Health Policy and Planning 20: 252-9.

Hutubessy R, Chisholm D, Edejer TT. 2003. Generalized cost-effectiveness analysis for national-level priority-setting in the health sector. Cost Effectiveness and Resource Allocation 1: 8.

Intersalt Cooperative Research Group. 1988. Intersalt: an international study of electrolyte excretion and blood pressure. Results for 24 hour urinary sodium and potassium excretion. British Medical Journal 297: 319-28.

Khai GP, Viet LN, Son TP et al. 2008. Epidemiological survey of hypertension and its risk factors in Vietnam. Presentation at the World Health Organization's office, Hanoi, Vietnam.

Kottke TE, Gatewood LC, Wu SC et al. 1988. Preventing heart disease: is treating the high risk sufficient? Journal of Clinical Epidemiology 41: 1083-93.

Lauer JA, Rohrich K, Wirth H et al. 2003. PopMod: a longitudinal population model with two interacting disease states. Cost Effectiveness and Resource Allocation 1: 6.

Law MR, Frost CD, Wald NJ. 1991. By how much does dietary salt reduction lower blood pressure? III. Analysis of data from trials of salt reduction. British Medical Journal 302: 819-24.

Levy DT, Bales S, Lam NT et al. 2006. The role of public policies in reducing smoking and deaths caused by smoking in Vietnam: results from the Vietnam tobacco policy simulation model. Social Science o Medicine 62: 1819-30.

Lim SS, Gaziano TA, Gakidou E et al. 2007. Prevention of cardiovascular disease in high-risk individuals in low-income and middle-income countries: health effects and costs. The Lancet 370: 2054-62.

MacMahon S, Peto R, Cutler J et al. 1990. Blood pressure, stroke, and coronary heart disease. Part 1, Prolonged differences in blood pressure: prospective observational studies corrected for the regression dilution bias. The Lancet 335: 765-74.

MacMahon S, Rodgers A. 1993. The effects of antihypertensive treatment on vascular disease: reappraisal of the evidence in (1994). Journal of Vascular Medicine and Biology 4: 265-5.

MOH. 2003. Report on results of the Vietnam National Health Survey 2001-2002. Hanoi: Ministry of Health and General Statistics Office of Vietnam.

MOH. 2007. Prevention of Hypertension Project for the period 2008-2010. Hanoi: Ministry of Health of Vietnam.

MOH. 2008. Joint Annual Health Review 2008: Health Financing in Viet Nam. Hanoi: Ministry of Health of Vietnam.

MSH. 2007. International Drug Price Indicator Guide. Boston, MA: Management Sciences for Health.

Murray CJ, Evans DB, Acharya A et al. 2000. Development of WHO guidelines on generalized cost-effectiveness analysis. Health Economics 9: 235-51.

Murray CJL, Lauer JA, Hutubessy RCW et al. 2003. Effectiveness and costs of interventions to lower systolic blood pressure and 
cholesterol: a global and regional analysis on reduction of cardiovascular-disease risk. The Lancet 361: 717-25.

Neal B, MacMahon S, Chapman N. 2000. Effects of ACE inhibitors, calcium antagonists, and other blood-pressure-lowering drugs: results of prospectively designed overviews of randomised trials. Blood Pressure Lowering Treatment Trialists' Collaboration. The Lancet 356: 1955-64.

Nishtar S. 2002. Prevention of coronary heart disease in south Asia. The Lancet 360: 1015-8.

O'Connor PJ. 2003. Overcome clinical inertia to control systolic blood pressure. Archives of Internal Medicine 163: 2677-8.

Patrono C, Coller B, FitzGerald GA et al. 2004. Platelet-active drugs: the relationships among dose, effectiveness, and side effects: the Seventh ACCP Conference on Antithrombotic and Thrombolytic Therapy. The American College of Chest Physicians 126: 234-64.

Prospective Studies Collaboration. 1995. Cholesterol, diastolic blood pressure, and stroke: 13,000 strokes in 450,000 people in 45 prospective cohorts. The Lancet 346: 1647-53.

Puska P, Salonen JT, Nissinen A et al. 1983. Change in risk factors for coronary heart disease during 10 years of a community intervention programme (North Karelia project). British Medical Journal (Clinical Research Edition) 287: 1840-4.

Rose G, Khaw KT, Marmot M. 2008. Rose's Strategy of Preventive Medicine: The Complete Original Text. New York: Oxford University Press.

Rubinstein A, Martí SG, Souto A et al. 2009. Generalized costeffectiveness analysis of a package of interventions to reduce cardiovascular disease in Buenos Aires, Argentina. Cost Effectiveness and Resource Allocation 7: 10.

Stein EA, Lazkarzewski P, Steiner P. 1993. Lovastatin 5-year safety and efficacy study. Archives of Internal Medicine 153: 1079-87.
Tian HG, Guo ZY, Hu G et al. 1995. Changes in sodium intake and blood pressure in a community-based intervention project in China. Journal of Human Hypertension 9: 959-68.

Tikkanen MJ, Helve E, Jäättelä A et al. 1988. Comparison between lovastatin and gemfibrozil in the treatment of primary hypercholesterolemia: the Finnish Multicenter Study. The American Journal of Cardiology 62: 35J-43J.

Tsugane S. 2005. Salt, salted food intake, and risk of gastric cancer: epidemiologic evidence. Cancer Science 96: 1-6.

Tsugane S, Sasazuki S, Kobayashi M et al. 2004. Salt and salted food intake and subsequent risk of gastric cancer among middle-aged Japanese men and women. British Journal of Cancer 90: 128-34.

Tuan NT, Tuong PD, Popkin BM. 2008. Body mass index (BMI) dynamics in Vietnam. European Journal of Clinical Nutrition 62: 78-86.

UN-EU. 2007. UN-EU Guidelines for Financing of Local Costs in Development Co-operation with Vietnam. UN Agencies, the Embassies of the EU Member States, and the EC Delegation to Vietnam.

WHO. 2001. Macroeconomics and Health: Investing in Health for Economic Development. Geneva: World Health Organization.

WHO. 2002. The World Health Report 2002: Reducing Risks, Promoting Healthy Life. Geneva: World Health Organization.

WHO. 2007. Reducing Salt Intake in Populations: Report of a WHO Forum and Technical Meeting. Geneva: World Health Organization.

Williams B. 2006. Evolution of hypertensive disease: a revolution in guidelines. The Lancet 368: 6-8. 